\title{
Trace Column of Contrast or Air Between Tongue Base and Posterior Pharyngeal Wall During Swallowing
}

National Cancer Institute

\section{Source}

National Cancer Institute. Trace Column of Contrast or Air Between Tongue Base and Posterior Pharyngeal Wall During Swallowing. NCI Thesaurus. Code C127326.

A finding of a trace column of contrast or air between tongue base and posterior pharyngeal wall during swallowing. 